\title{
Abdominal Pregnancy: Epidemiological, Diagnostic, Therapeutic and Prognostic Aspects: A Case Report from the Yaounde Central Hospital (Cameroon)
}

\author{
Armand Kamga Talom ${ }^{1 *}$, Florent Fouelifack Ymele ${ }^{2,3}$, Madye Ngo Dingom², \\ Jeanne Fouedjio ${ }^{1,2}$ \\ ${ }^{1}$ Department of Obstetrics and Gynaecology, Faculty of Medicine and Biomedical Sciences, \\ University of Yaounde I, Cameroon \\ ${ }^{2}$ Yaounde Central Hospital, Cameroon \\ ${ }^{3}$ Higher Institute of Medical Technology, Yaounde, Cameroon \\ Email: ^kamtalar@gmail.com, yfouelifack@gmail.com,dingom20022003@yahoo.fr, fouedjiojeanne@yahoo.fr
}

How to cite this paper: Kamga Talom, A., Ymele, F.F., Dingom, M.N. and Fouedjio, J. (2021) Abdominal Pregnancy: Epidemiological, Diagnostic, Therapeutic and Prognostic Aspects: A Case Report from the Yaounde Central Hospital (Cameroon). Open Journal of Obstetrics and Gynecology, 11, 381-390.

https://doi.org/10.4236/ojog.2021.114038

Received: March 14, 2021

Accepted: April 19, 2021

Published: April 22, 2021

Copyright $\odot 2021$ by author(s) and Scientific Research Publishing Inc. This work is licensed under the Creative Commons Attribution International License (CC BY 4.0).

http://creativecommons.org/licenses/by/4.0/

\begin{abstract}
Abdominal pregnancy (AP) is a relatively rare and potentially serious form of ectopic pregnancies (EPs). We report the case of a haemorrhagic abdominal pregnancy at 15 weeks of amenorrhea complicated by hypovolaemic shock, with a favorable outcome. Our aim is to outline the epidemiological, clinical, therapeutic and prognostic features of this condition.
\end{abstract}

\section{Keywords}

Abdominal Pregnancy, Epidemiology, Prognosis, Yaoundé, Cameroon

\section{Introduction}

Abdominal pregnancy (AP) is defined as the implantation and development of the fertilized egg in the peritoneal cavity. The actual incidence of this medical and surgical entity is not well defined according to different authors, and it is more marked in Africa than in developing countries. However, it remains a rather rare and serious condition requiring multidisciplinary management.

We report the case of a haemorrhagic abdominal pregnancy at 15 weeks of amenorrhea complicated by hypovolaemic shock, with a favourable outcome. The aim here is to recall the epidemiological particularities and to expose the clinical, therapeutic and prognostic aspects of this condition. 


\section{Patient and Observation}

We report the case of an abdominal pregnancy in a 36-year-old single female hairdresser, delivered at 14 weeks of amenorrhea (WA) and 03 days (D) of the theoretical term. She has a history of 03 normal deliveries at term by vaginal route for a total of 4 gestures. She has a regular menstrual cycle of 31 days. She had her first sexual intercourse at the age of 17 . She has had 5 cumulative sexual partners and currently has 01 . She does not use contraceptive methods and has unprotected sex. She had never been screened for sexually transmitted infections.

She was referred to us from a local district medical center for better management of an abdominal pregnancy (GA). Two weeks earlier, the patient presented with postprandial nausea and vomiting, without fever, accompanied by a small amount of blackish per vaginal bleeding. A few days later she experienced mild abdominal pain of progressive onset, an increase in abdominal volume, the perception of fetal movements, moderate asthenia and dizziness. Thus motivating a consultation in the said medical center where an abdominopelvic ultrasound was performed, showing an evolving abdominal pregnancy of $15 \mathrm{WA}+04 \mathrm{D}$, located at the limit of the right flank (RF) and the right iliac fossa (RIF) and a large amount of haemoperitoneum. Faced with these findings and with a limited technical platform, the medical center immediately referred the patient to us.

When we saw the patient, she was complaining of asthenia and generalized abdominal pain. She did not have any breakthrough bleeding. Her blood pressure was 100/70 $\mathrm{mmHg}$, her pulse rate was 104 beats per minute, her temperature was 37.4 degrees Celsius, and her respiratory rate was 24 cycles per minute. The conjunctiva was pale. The abdomen was undistended, mobile with respiration. We noted marked abdominal tenderness to palpation on RIF and RF with a mass of approximately $16 \mathrm{~cm}$ long axis, umbilical rebound tenderness, and a sloping dullness. The fetal heart sounds (FHS) were perceptible and tachycardic at $172 \mathrm{bpm}$. On gynaecological examination, we observed on speculum, a macroscopically normal purplish cervix, no bleeding was observed. On digital vaginal examination, the cervix was posterior, long, closed, mobilisation of the cervix was not painful, the uterus was of the normal size, the adnexa was slightly tender without palpable masses. In addition, the posterior fornix was slightly bulging and sensitive. An emergency blood count showed a haemoglobin level of $4.9 \mathrm{~g} / \mathrm{dl}$ and platelets of $270,000 / \mu \mathrm{l}$. We concluded that the pregnancy was a haemorrhagic abdominal pregnancy complicated by severe anaemia at an ultrasound term of $15 \mathrm{WA}+04 \mathrm{D}$.

The initial management consisted of counselling, conditioning of the patient with 2 large-bore venous lines and reservation of 2 blood bags, emergency laparotomy under general anaesthesia with oeso-thracheal intubation. The preoperative check-up was normal. We concomitantly prepared for an intraoperative auto-transfusion.

Findings at emergency laparotomy were: Hemoperitoneum of about $2000 \mathrm{ml}$; Abdominal pregnancy in the RF with live fetus and placenta adhered largely to the omentum and partially to the colon, right fringe and contralateral ovary 
(Figure 1), we noted active bleeding from the placenta, the contralateral tube was macroscopically normal, fetus + placenta block weighed $220 \mathrm{~g}$. The uterus was of normal size and the pelvis was adherent with Fitz-Hug-Curtis syndrome.

The intraoperative procedures consisted of: Aspiration of $600 \mathrm{ml}$ of haemoperitoneum for autotransfusion (Figure 2) and the rest of the haemoperitoneum; careful digital adhesiolysis of the placenta on the left omentum, colon and ovary, clamping and a partial right salpingectomy (Figure 3 and Figure 4). Finally, we placed a parietal drain.

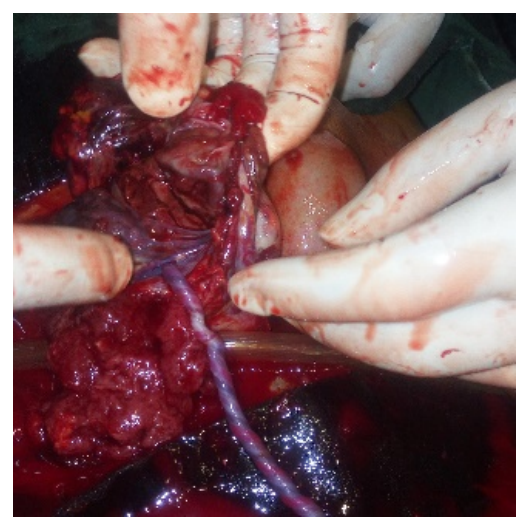

Figure 1. Adhesion to the omentum.

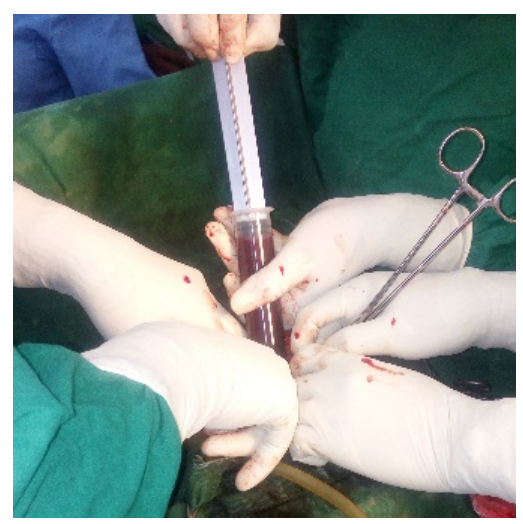

Figure 2. Blood collection for auto-transfusion.

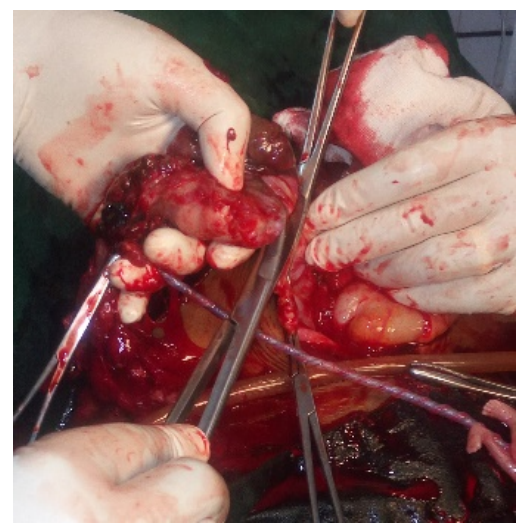

Figure 3. Right partial salpingectomy. 


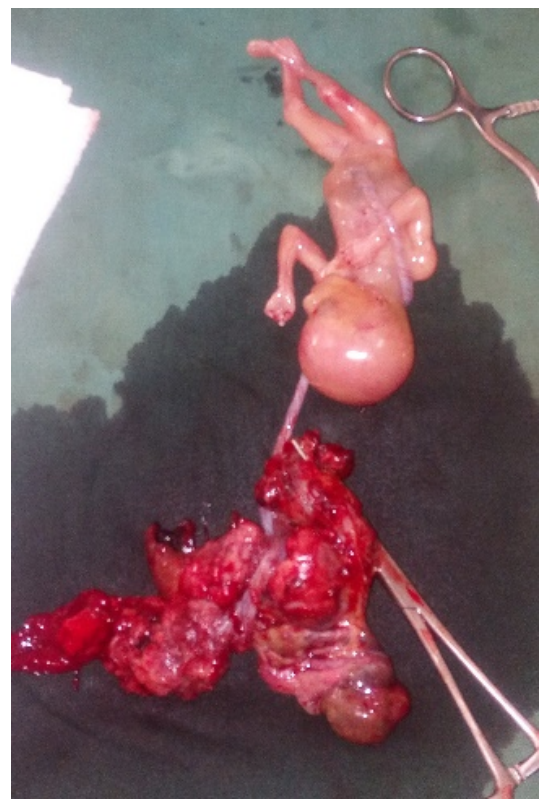

Figure 4. Fetus with part of the placenta and tube.

The postoperative follow-up was marked by stabilisation of vital parameters on Day 1, and a transfusion of 2 blood bags on Day 2. Due to a lack of funds, the patient was not able to undergo the pre-therapeutic check-up until after 7 days. The parietal drain was removed at D8 and she received a dose of methotrexate 1 $\mathrm{mg} / \mathrm{kg} /$ dose at D9. The patient was discharged on the tenth postoperative day.

\section{Discussion}

AP accounts for $1 \%$ of all EPs. In developed countries, its incidence is 1 per 10,000 live births [1] [2]. Compared to developing countries, particularly in Africa, it is less rare and its frequency varies from $0.009 \%$ in Morocco to $0.152 \%$ in Nigeria (Table 1) [3]-[9]. No statistical data from Cameroon was found in the literature.

A distinction is made between primary AP with primary implantation of the egg in the abdominal cavity and secondary AP where trophoblastic implantation occurs by grafting into the abdominal cavity after a tubal abortion [10]. Studdiford described 3 criteria for primary AP: Normal adnexa, with no evidence of recent injury; Absence of uteroperitoneal fistula; strictly peritoneal location of a pregnancy less than 12 weeks old. It may be pelvic (Posterior fornix, fundus or posterior aspect of the uterus) as well as abdominal (diaphragm, liver, spleen, omentum), or even retroperitoneal [11]; the clinical presentation of AP is similar to that of first trimester EP [12]. Secondary AP, which is usually diagnosed later in pregnancy, appears to be more common. In practice, this classification is controversial as it is often difficult to establish and of little clinical interest. Classification according to the term is preferred. A distinction is made between early and advanced AP diagnosed after 20 days' gestation [13]. Our patient probably had early secondary AP. 
Table 1. Frequency distribution of abdominal pregnancy.

\begin{tabular}{ccc}
\hline Authors (Countries) & Cas (n) & Percentage (\%) \\
\hline Bouaziz N (Tunisia) & 1 & 0.013 \\
Alami A (Morocco) & 4 & 0.009 \\
Yinde A (Nigeria) & 14 & 0.152 \\
Iloki LH (Congo) & 9 & 0.043 \\
Diouf A (Senegal) & 2 & 0.09 \\
Bang Ntamack (Gabon) & 19 & 0.022 \\
\hline
\end{tabular}

Concerning the risk factors, those of EP are generally found: infertility, intrauterine device, pregnancy after in vitro fertilisation (IVF); a history of traumatic endo-uterine maneuvers: voluntary interruption of pregnancy by suction [14], uterine scar of AP with recurrence of advanced AP of the same location [15], segmental or segmento-corporeal caesarean section scar [16] [17]. Anecdotally, AP after hysterectomy has also been described: 29 cases reported in the literature in 1984 [18]. None of these risk factors was found in our patient. However, she is now at risk of another AP.

The preoperative diagnosis of AP is difficult, the non-specific nature of the symptoms, the clinical polymorphism linked to the diagnostic term, the low profitability of traditional imaging and its scarcity explain why, in $50 \%$ of cases, its discovery will be fortuitous during the operation. On the maternal side, there is often an episode of paroxysmal abdominopelvic pain at the beginning of pregnancy followed by an unexplained chronic algesic background. Various signs should call for attention: persistent nausea and vomiting, metrorrhagia, anaemia contrasting with the modest nature of the metrorrhagia, as in our patient's case. The diagnosis is sometimes made during the management of a massive haemoperitoneum in an unrecognised pregnancy. On the fetal level, the discovery of oligohydramnios, decreased active fetal movements (AFM), unexplained in utero fetal death (IUFD), painful AFM, unexplained intrauterine growth retardation, and permanent transverse presentation should raise the diagnosis. In our patient, we only noted the presence of AFM and tachycardic FHS. On clinical examination, an impression of a fetus "moulded" by the abdominal wall or, conversely, poorly defined "uterine" contours are sought. Pain on palpation with a parietal reaction can sometimes suggest a contractile uterus. Our patient had a painful parietal reaction on abdominal palpation. On vaginal touch, the cervix is usually retro symphyseal, which was not the case in our patient. Palpation of the empty uterus is difficult. Ultrasound provides precious information and sometimes brings the diagnosis when faced with unexplained oligohydramnios, a fetus not circumscribed by the myometrium, visualisation of the empty uterus (often considered a "pelvic mass": fibroid, ovarian cyst, uterine malformation...). The ultrasound contribution is crucial, evoking the diagnosis 
and indicating magnetic resonance imaging (MRI). However, it should not be forgotten that in the majority of countries in the world MRI is not accessible: ultrasound is, therefore, the decisive imaging examination [3] [19]. The diagnosis of AP is, therefore, difficult and requires "thinking ectopic" as recommended by Moonen [20].

Regarding the therapeutic aspect, most authors recommend laparotomy once the diagnosis has been made, regardless of the fetal status, given the unpredictable and serious nature of maternal complications occurring at any term [1] [21] [22]. For Costa, a conservative approach is questionable from 24 WA [23]. Martin proposed in 1990 a list of 7 criteria required to propose conservative treatment for AP diagnosed after 20 WA [24]: Absence of malformation; Absence of signs of maternal or fetal decompensation; Monitoring of fetal well-being; Placental insertion in the lower abdomen; Distance from the liver and spleen; Presence of amniotic fluid around the fetus; Continuous hospitalisation in a suitable facility; Informed consent of the patient. Our patient was not immediately eligible for the conservative approach due to the term of the pregnancy.

In practice, if the diagnosis is made before $20 \mathrm{WA}$, termination of the pregnancy will be discussed, and derogation from this attitude must remain exceptional. If the decision is made to maintain the pregnancy, hospitalisation in a suitable facility until birth is required. The term of programmed laparotomy varies in the literature: Ombelet in a series of 38 cases in 1988 recommended 34 WA [25]. This term seems reasonable given the current possibilities of management by neonatologists (corticosteroids, surfactant, etc.). During laparotomy, carried out by a surgical team with skills adapted to the risk of haemorrhage and the possibility of a digestive, urinary or vascular surgical procedure, the problem of the high risk of haemorrhage during delivery will arise [26] [27] [28].

The rate of delivery in the case of AP is estimated after reviewing the literature at 60\% [25]. Pre-operative assessment of the placental site is based on MRI, which provides the best indication of the insertion site. MRI can also provide other information (vascular relationships, visualisation of infarction) [29]. In his series of three cases, Shumway noted that an elevated alpha-fetoprotein level is suggestive of an extensive placental insertion site at high risk of bleeding [30]. In our case we did not have an MRI scan and also did not perform an alpha-fetoprotein assay.

There are three possibilities: 1) Delivering the placenta during laparotomy when this is feasible; 2) Leaving the placenta in situ after proximal cord ligation and waiting for spontaneous resorption monitored by echo-Doppler [31] [32] and b-HCG; 3) Or leaving the placenta in situ and adding methotrexate treatment.

The place of embolisation remains to be clarified: Kerr noted in a series of three cases the interest of preoperative embolisation allowing in each case a delivery at the cost of a modest haemorrhage without subsequent complications [33]. Martin published a case of embolisation performed on day 1 of laparotomy with placenta left in situ complicated by secondary haemorrhage [34]. 
Placental resorption is slow [35], secondary complications have been described, but are uncommon (secondary haemorrhage, sub-occlusive syndrome, sepsis, ureteral obstruction [36], choriocarcinoma). Hreshchyshyn reported in a series of 101 cases with $71 \%$ delivery at laparotomy a significantly reduced rate of surgical revision and re-hospitalisation [37]. We insist on a precise anaesthetic and resuscitation protocol that is particularly useful in the case of emergency laparotomy. Our patient's postoperative course up to 9 days post-op was simple.

Regarding the prognosis, AP is responsible for perinatal mortality of between 40 and $95 \%$ [1]. Maternal mortality is 5.2\%o [38]. Its early diagnosis considerably reduces the maternal risk [1].

\section{Conclusion}

Abdominal pregnancy is an extremely rare condition in developed countries. However, it still remains a reality in our regions. It poses a real diagnostic and therapeutic problem. Depending on the term and the clinical presentation, the therapeutic approach can be conservative or interventional. This high-risk maternal and fetal pregnancy must be approached on a case-by-case basis by a multidisciplinary team.

\section{Authors' Contributions}

The authors of the manuscript have read and approved the contents of the manuscript. All authors also declare to have read and approved the final version of the manuscript.

\section{Conflicts of Interest}

The authors declare no conflicts of interest regarding the publication of this paper.

\section{References}

[1] Atrash, H.K., Friede, A. and Hogue, C.J.R. (1987) Abdominal Pregnancy in the United States: Frequency and Maternal Morbidity. Obstetrics and Gynecology, 69, 333-337.

[2] Bénifla, J.L., Bardou, D., Sebban, E., Daraï, E. and Madelenat, P. (1997) Masson Éditeur. La grossesse extra- utérine chapitre, 6, 38-46.

[3] Diouf, A., Diouf, F., Cisse, C.T., Diaho, D., Gaye, A. and Diadhiou, F. (1996) La grossesse abdominale à terme avec enfant vivant. À propos de deux observations. Journal de Gynécologie Obstétrique et Biologie de la Reproduction, 25, 212-215.

[4] Institut National de la Statistique (INS) et ICF (2020) Enquête Démographique et de Santé du Cameroun 2018. INS et ICF, Yaoundé, Cameroun et Rockville, Maryland, USA, 377-385.

[5] Bouaziz, N., Zhioua, F., Chaker, A., Mouelhi, C., Ferehiou, M. and Meriah, S. (1997) Un nouveau cas de grossesse abdominal avec enfant vivant et non malformé. La Tunisie medicale, 75, 143-145.

[6] Iloki, L.H., Koubaka, R., Nkihouabonga-Guinot, G., Ibara, J.R. and Ekouddzola, J.R. 
(1999) Grossesse Abdominale. Neuf cas colligés en quatre ans (1991/1995) au CHU de Brazzaville (Congo). Revue française de gynécologie et dobstétrique, 94, 40-43.

[7] Yinde, A.O.A., Imakhu, C.O.A., Deyanju, O.A.A. and Migbodun, A.O.O. (2005) Abdominal Pregnancy at the University College Hospital, Ibadan: A 10-Year Review. African Journal of Reproductive Health, 9, 123-127. https://doi.org/10.2307/3583166

[8] Adjahoto, E.O., Attignon, A. and Kodonou, A.K.S. (2002) Grossesse Abdominale: étude d'une série de onze cas. Revue Medicale de la Suisse Romande, 122, 39-42.

[9] Bang Ntamack, J.A., Ngou Mve Ngou, J.P., Sima Ole, B., Sima Zue, A., Mayi Tsonga, S. and Meye, J.F. (2012) Grossesse Abdominale à Libreville de 1999 à 2009. Journal de Gynecologie Obstetrique et Biologie de la Reproduction, 41, 83-87.

[10] Alto, W.A. (1990) Abdominal Pregnancy. American Family Physician, 41, 209-214.

[11] Ferland, R.J., Chadwick, D.A., O’Brien, J.A. and Granai III, C.O. (1991) An Ectopic Pregnancy in the Upper Retroperitoneum Following in Vitro Fertilization and Embryo Transfer. Obstetrics and Gynecology, 78, 544-546.

[12] Hallat, J.G. and Grove, J.A. (1985) Abdominal Pregnancy: A Study of Twenty-One Consecutive Cases. American Journal of Obstetrics and Gynecology, 152, 444-449. https://doi.org/10.1016/S0002-9378(85)80155-1

[13] Martin Jr., J.N., Sessums, J.K., Martin, R.W., Pryor, J.A. and Morrisson, J.C. (1988) Abdominal Pregnancy: Current Concepts of Management. Obstetrics \& Gynecology, 71, 549-557.

[14] Hainaut, F., Mayenga, J.M. and Crimail, P. (1991) Grossesse Abdominale Tardive. À propos d'un cas. Revue française de gynécologie et dobstétrique, 86, 522-528.

[15] Nehra, P.C. and Loginski, S.J. (1984) Pregnancy after Vaginal Hysterectomy. Obstetrics \& Gynecology, 64, 735-738.

[16] Jackson, P., Barrowclough, I.W., France, J.T. and Phillips, L.I. (1980) A Successful Pregnancy Following Total Hysterectomy. BJOG: An International Journal of Obstetrics \& Gynaecology, 87, 353-355. https://doi.org/10.1111/j.1471-0528.1980.tb04557.x

[17] Tan, K.L., Vengadasalam, D. and Leon, T.H. (1971) Recurrent Abdominal Pregnancy. BJOG: An International Journal of Obstetrics \& Gynaecology, 78, 1044-1046. https://doi.org/10.1111/j.1471-0528.1971.tb00223.x

[18] Neiger, R., Weldon, K. and Means, N. (1998) Intra Mural Pregnancy in a Cesarean Section Scar. A Case Report. The Journal of Reproductive Medicine, 43, 999-1001.

[19] Sfar, E., Kaabar, H., Marrakechi, O., Zouari, F., Chelli, H., Kharouf, M., et al. (1993) La grossesse abdominale, entité anatomoclinique rare. À propos de quatre cas (1981-1990). Revue Française de Gynecologie et d Obstétrique, 88, 261-265.

[20] Moonen Delarue, M.W.G. and Haest, J.W.G. (1996) Ectopic Pregnancy Three Times in Line of Which Two Advanced Abdominal Pregnancies. European Journal of $O b$ stetrics \& Gynecology and Reproductive Biology, 66, 87-88.

https://doi.org/10.1016/0301-2115(96)02388-3

[21] Strafford, J.C. and Ragan, W.D. (1977) Abdominal Pregnancy Review of Current Management. Obstetrics \& Gynecology, 50, 548-552.

[22] Delke, I., Veridiano, N.P. and Tancer, M.L. (1982) Abdominal Pregnancy: Review of Current Management and Addition of Ten Cases. Obstetrics \& Gynecology, 60, 200-204.

[23] Costa, S.D., Presley, J. and Bastert, G. (1991) Advanced Abdominal Pregnancy. Obstetrical \& Gynecological Survey, 46, 515-525. 
https://doi.org/10.1097/00006254-199108000-00003

[24] Martin Jr., J.N. and McCaul, I.V.J.F. (1990) Emergent Management of Abdominal Pregnancy. Clinical Obstetrics and Gynecology, 33, 438-447.

https://doi.org/10.1097/00003081-199009000-00008

[25] Ombelet, W., Vandermerwe, J.V. and Van Assche, F.A. (1988) Advanced Extra-Uterine Pregnancy: Description of 38 Cases with Literature Survey. Obstetrical \& Gynecological Survey, 43, 386-397. https://doi.org/10.1097/00006254-198807000-00003

[26] Hage, M.L., Wall, L.L. and Killiam, D.P.A. (1988) Expectant Management of Abdominal Pregnancy. A Report of Two Cases. Journal of Reproductive Medicine, 33, 407-410.

[27] Yu, S., Penissi, J.A., Moukhtar, M. and Friedman, E.A. (1995) Placental Abruption in Association with Advanced Abdominal Pregnancy. A Case Report. Journal of Reproductive Medicine, 40, 731-735.

[28] Vela, V. and Teo, J. (2001) Term Viable Abdominal Pregnancy: A Case Report and Review. Australian and New Zealand Journal of Obstetrics and Gynaecology, 41, 344-345. https://doi.org/10.1111/j.1479-828X.2001.tb01245.x

[29] Malian, V. and Lee, J.H.E. (2001) MR Imaging and MR Angiography in an Abdominal Pregnancy with Placental Infarction. American Journal of Roentgenology, 177, 1305-1306. https://doi.org/10.2214/ajr.177.6.1771305

[30] Shumway, J.B., Greenspoon, J.S., Khouzami, A.N., Platt, L.D. and Blakemore, K.J. (1996) Amniotic Fluid Alpha Fetoprotein (AFAFP) and Maternal Serum Alpha Fetoprotein (MSAFP) in Abdominal Pregnancies: Correlation with Extent and Site of Placental Implantation and Clinical Implications. The Journal of Maternal-Fetal Medicine, 5, 120-123.

https://doi.org/10.1002/(SICI)1520-6661(199605/06)5:3\%3C120::AID-MFM4\%3E3. $\underline{0 . \mathrm{CO} ; 2-\mathrm{O}}$

[31] Bajo, J.M., Garcia-Frutos, A. and Huertas, A. (1996) Sonographic Follow-Up of a Placenta Left in Situ after Delivery of the Fetus in an Abdominal Pregnancy. Ultrasound in Obstetrics \& Gynecology, 7, 285-288. https://doi.org/10.1046/j.1469-0705.1996.07040285.x

[32] Spanta, R., Roffman, L.E., Grissom, T.J., Newland, J.R. and McManus, B.M. (1987) Abdominal Pregnancy: Magnetic Resonance Identification with Ultrasonographic Follow-Up of Placenta Involution. American Journal of Obstetrics and Gynecology, 157, 887-889. https://doi.org/10.1016/S0002-9378(87)80079-0

[33] Kerr, A., Trambert, J., Mikhail, M., Hodges, L. and Runowicz, C. (1993) Preoperative Transcatheter Embolization of Abdominal Pregnancy: Report of Three Cases. Journal of Vascular and Interventional Radiology, 4, 733-735. https://doi.org/10.1016/S1051-0443(93)71960-0

[34] Martin Jr., J.N., Ridgway III, L.E., Connors, J.J., Sessums, J.K., Martin, R.W. and Morrison, J.C. (1990) Angiographic Arterial Embolization and Computed Tomography-Directed Drainage for the Management of Hemorrhage and Infection with Abdominal Pregnancy. Obstetrics \& Gynecology, 76, 941-945.

https://doi.org/10.1097/00006250-199011000-00053

[35] Belfar, H.L., Kurtz, A.B. and Wapner, R.J. (1986) Long-Term Follow-Up after Removal of an Abdominal Pregnancy: Ultrasound Evaluation of the Involuting Placenta. Journal of Ultrasound in Medicine, 5, 521-523.

https://doi.org/10.7863/jum.1986.5.9.521

[36] El Kareh, A., Beddoe, A.M. and Brown, B.L. (1993) Abdominal Pregnancy Compli- 
cated by Bilateral Ureteral Obstruction. A Case Report. The Journal of Reproductive Medicine, 38, 900-902.

[37] Hreshchyshyn, M.M., Bogen, B. and Loughran, C.H. (1961) What Is the Actual Present-Day Management of the Placenta in Late Abdominal Pregnancy? Analysis of 101 Cases. American Journal of Obstetrics and Gynecology, 81, 302-317.

[38] Gradzinskas, J.G. (1999) Abdominal Pregnancy. In: Edmond, O.K., Ed., Dew Hurst's Text Book of Obstetrics and Gynaecology for Post Graduates, Black Well, Edinburgh, 70. 